\title{
An Italian National Curriculum on ICT for Schools
}

\author{
Giuseppe Callegarin and Agostino Cortesi \\ Istituto Regionale di Ricerca Educativa del Veneto, Mestre-Venezia, Italy \\ g.callegarin@irrsae.veneto.it \\ Dipartimento di Informatica, Università Ca' Foscari di Venezia, Mestre-Venezia, Italy
}

Keywords: primary education, secondary education, computer science, didactics

\begin{abstract}
This paper reports a contribution towards the definition of a new ICT National Italian Curriculum for both Primary and Secondary Schools. A method is proposed that supports the generation of the ICT Curriculum for each year or stage, with a convincing solid theoretical and pragmatic foundation. The key idea is to iterate progressively around some general operations on information: searching, analysing, structuring, processing, presenting and communicating. At each iteration, we suggest some contents, abilities and tools. Preliminary experimental results on the application of this method have been very promising, giving evidence of its effectiveness.
\end{abstract}

\section{INTRODUCTION}

Designing an ICT National Curriculum is a challenging task for several including the rapid evolution of hardware and software, because ICT is not yet accepted by many teachers as a discipline, and because of the required teacher competence. Moreover, some possible negative consequences of ICT on education and public investment (Stoll 1999) must be taken into account. Italy, along with many other countries, has been facing this challenge.

Italy is going to take a critical step as part of its reform of the whole School System. A recent law (Italian Parliament 2000) established that Primary School, called 'scuola di base', will cover 7 years (including Elementary School) and Secondary School will cover 5 years. The 
curriculum of the Secondary School will be divided into four main areas: Classic-Humanistic, Scientific, Technical and Technological, Artistic and Musical. The first two years of each area should provide some common background.

This reform is intended to enable people to find a job more quickly after compulsory school, and follows the example of many European countries. This reform also provides a chance critically redefine the aims of education, the need and role of traditional subjects, and the growth of new subjects.

A key concept that has been clearly identified is that any person after the Secondary School should possess certain skills. A skill is a suitable set of knowledge and abilities over a field (e.g. economics, foreign languages.) which enables a person to be 'competent' in some field regardless of the context in which they will work.

ICT skill has been considered relevant since the first analysis: basic education cannot ignore the new ways of building, communicating and presenting information. In this regard, Italy seems to be late compared with other countries that have had an ICT National Curriculum for several years, e.g. the UK (1999). Some critical decisions have then to be made in 2001/2002 in order to establish an ICT National Curriculum for Italy.

Until now, ICT has been taught as a subject for study only in a few Technical Secondary Schools. Some aspects of ICT have also been taught in almost every school (typically within Mathematics and Physics in the age range 14-15), with a variety of results.

This paper reports a contribution to help the task force called to propose the new ICT National Curriculum for both Primary and Secondary Schools (Infant School will also be closely involved). The aim is the definition of a method capable of 'generating' the ICT Curriculum for each year or stage in some detail and with a convincing solid theoretical and pragmatic foundation. With regard to the 'state of the art' on ICT, our main reference is the Computing Curricula 2001, jointly proposed by IEEE and ACM (IEEEACM 2000), the two biggest professional associations in the field.

The key idea of our proposal is to iterate progressively around some general operations on information: searching, analysing, structuring, processing, presenting and communicating. At each iteration we suggest some contents, abilities and tools. In this way, we aim at covering the basic aspects of four main ICT areas: data, programming, systems and languages.

The rest of this paper is structured as follows. The next section will describe the constraints to be overcome for the establishment of an Italian ICT National Curriculum for the compulsory school to be effective. In the subsequent section our model is introduced. Then a case study is discussed, that describes the application of our model for generating the curriculum of 
the first years of the Secondary School (age 13-14). Finally we will mention a didactic experience in a Primary School following the proposed model.

\section{CONSTRAINTS}

In this section, we briefly discuss the main constraints any curriculum proposal for Primary and Secondary Italian schools have to take into account in order to be effective.

How many years of school? In the new setting, Infant, Primary and Secondary schools will be organised into three cycles: 3 to 5 years, 6 to 13 , and 13 to 18 . Even though some very preliminary idea can be experimented in the first cycle, our proposal focuses just on the second and third cycles, covering the 12 years of compulsory school.

How many hours per year? We assume that between 30 and 40 hours will be assigned to ICT strongly related activities.

Which kind of teachers are available? Unfortunately, at the moment many teachers enrolled have a poor, if any, background in Computer Science. Therefore, this proposal needs to be shared, understood and appreciate by all of them first, otherwise it will result in something totally useless.

Which kind of tools are currently available in the schools? Computer systems change rapidly and quickly become obsolete. this is a serious problem, and often results in poor investment policies (and a museum of obsolete laboratories that in many cases have rarely been used). The best way to tackle this problem is to maintain very small computer laboratories. In addition, incentives for families to buy computers, mostly as an educational tool, should be included in any sensible public policy. In our proposal, we make very little assumptions about the tools available, and we believe that it is part of a teacher's duties to translate contents and methodologies in the particular school context.

What is the expected background of the pupils? Computers are mostly seen either as a support for video-games, or a way to access the Internet. However, pupils are totally unaware of its relevance, and in most cases we can assume basic abilities (e.g. interacting by properly using keyboard and mouse commands) that may often even precede and overrule reading and writing abilities.

Which are the peculiarities of the Italian education system? The Italian education system, like the economics and social systems, is anything but homogeneous. One of the main roles of the compulsory school is to promote a common background, in order to give all children the same cultural 
chances. On the other hand, any proposal has to take into account these differences, and flexibility is a key issue in this respect.

\section{A SPIRAL MODEL}

Speaking about ICT instead of 'Computer Science' is not just a matter of fashion. The emphasis is on the keywords 'information' and 'communication'. The reason for teaching, to the next generation, methodologies and tools coming from research in Computer Science, is not only demanded by the impact of new technologies on our daily life, but also by the intuition that technologies have a deep impact on the way pupils look at the world around them, a world where information is becoming crucial. Moreover, the way information is searched, analysed, structured, processed, presented and communicated is a valuable information.

The activities just mentioned are the keywords of our proposal. This leads to a spiral process as depicted in Figure 1, where the three iterations roughly correspond to the three main steps (Primary School, the 2 years stage of Secondary School, and finally the 3 years stage of Secondary School). Each cycle is followed by two crucial steps: verification with respect to the initial aims, and planning, to adapt the next cycle iteration to the specific class.

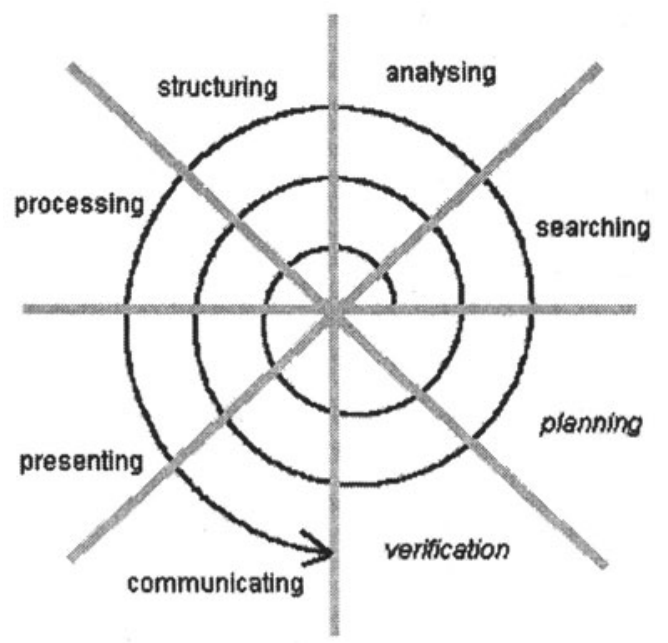

Figure 1. The spiral model 
Let us present in some detail the six phases of each iteration.

Searching. Questions like "what kind of information is available?" and "what I'm really looking for?" can be considered as starting points. In Primary School, these questions would lead to activities that emphasise the crucial role of selecting research keys, and of verifying the matching between aims and results. Then, in the following years, they move to the introduction of basic ideas about the different ways a database may be structured, in order to design and tune effective queries. At a further step, useful ideas on searching techniques in semi-structured databases, like the web, must be introduced in the Secondary School.

Analysing. Analysis means interpreting, i.e. getting to the semantics. The basic step here is decoding the information from its source, and navigating the information space looking at the contents more than on the syntactical aspects.

Structuring. Information structuring includes several aspects: data presentation, motivations for using tables, functional lists, spreadsheets, whether data oriented or event oriented. The concepts of information hiding and other data abstraction processes are also included here.

Processing. Design and Programming are the main skills that are considered here. The main problem-solving strategies can be introduced at different depth levels. The idea of procedural abstraction can be gradually introduced, focusing on generalisation and specialisation methodologies. Basic algorithms can be presented and discussed with respect to correctness, efficiency, termination, usability, etc., by emphasising the independence of the design with respect to specific programming language issues. Then, the importance of expressing the solution of a problem (the algorithm) through the choice of a suitable (high or low) level programming language will be considered.

Presenting. The same effort that is necessary when analysing information (interpreting a message from its support) has to be put into the opposite direction, when choosing the way information has to be presented in order to be well understood. The key issue, in this respect, is the notion of interface.

Communicating. The last step is about how to share information with other people. Effective communication depends both on the quality of the information that is shared, and on the choice and correct use of communication tools. Security issues can also be taken into account.

The validation of the syllabus relies on the analysis of the way it covers the main Computer Science research areas, as depicted in the ACM-IEEE Computer Curricula 2001 (the draft version currently available), focusing in particular on the following areas.

- Data Representation and Management: hierarchical, relational and object oriented approaches to data representation organisation and retrieval; 
- Algorithms: problem solving - basic algorithmic strategies and complexity issues;

- Systems: system architectures - networks;

- Languages: syntax and semantics issues.

\section{A CASE STUDY: GENERATING AN ICT CURRICULUM FOR THE 13-14 YEAR STAGE}

Let us show an application of the method outlined in the previous section to 'generate' a curriculum valid for a central period of the school age: 13-14 years, i.e. the first two years of the Secondary School according to the new Italian system. This stage will act as a bridge between the Primary School and the final 3-year stage, to be chosen from among four areas.

Because of the variety of approaches and of the teachers' training, we need to verify the basic ICT competence that pupils get from the Primary School. At the same time, we have to improve the quality of their knowledge and introduce new concepts, abilities and tools. We can summarise the special constraints for this period as follows.

- To assess and consolidate the basic ICT competence that pupils get from Primary School;

- To cover each operation about information in a significant way;

- To ensure the ICT competence required to support documentation and communication in all subjects of the final 3-year stage;

- To cover the four main cross-ICT areas in a way that pupils can recognise ICT both as a Science and a Technology (this can help them in choosing the subsequent area and sub-area of study).

A solution satisfying all these constraints is reported in Tables 1 and 2. For each operation on information, the first table reports also an estimate percentage of all the time devoted to ICT. Decisions on how to build educational modules/units, or what to assign to the first or second year, could be postponed till a further refinement or decided by each school in the context of the autonomy the law now gives to each school. 
Table 1. Contents and abilities

\begin{tabular}{|c|c|c|}
\hline OPERATION & CONTENTS & ABILITIES \\
\hline $\begin{array}{l}\text { Searching } \\
(\sim 10 \%)\end{array}$ & $\begin{array}{l}\text { Data accessing modes: } \\
\text { sequential, direct, content driven. }\end{array}$ & $\begin{array}{l}\text { Accessing a database table by means } \\
\text { of the three access modes. } \\
\text { Proper use of search engines. }\end{array}$ \\
\hline $\begin{array}{l}\text { Analysing } \\
(\sim \mathbf{1 5 \%})\end{array}$ & $\begin{array}{l}\text { Syntax and semantics concepts. } \\
\text { The HTML case. } \\
\text { The image file case. }\end{array}$ & $\begin{array}{l}\text { Deciding the syntax correctness of a } \\
\text { text on the basis of a simple } \\
\text { grammar (e.g. a subset of the HTML } \\
\text { grammar). } \\
\text { Reading an HTML page at several } \\
\text { abstraction levels. Getting a picture } \\
\text { from a scanner and converting it into } \\
\text { several standard formats. }\end{array}$ \\
\hline $\begin{array}{l}\text { Structuring } \\
(\sim \mathbf{1 5 \%})\end{array}$ & $\begin{array}{l}\text { Hypertext/hypermedia, tables - } \\
\text { spreadsheets, trees, } \\
\text { hierarchical classification. }\end{array}$ & $\begin{array}{l}\text { Building hypertexts or hypermedia } \\
\text { from conceptual maps. } \\
\text { Basic uses of a spreadsheet. } \\
\text { Recognising the tree structure of } \\
\text { some information. }\end{array}$ \\
\hline $\begin{array}{l}\text { Processing } \\
(\sim \mathbf{3 0} \%)\end{array}$ & $\begin{array}{l}\text { The concepts of process, } \\
\text { processor, algorithm, program. } \\
\text { The "whathow-to" distinction. } \\
\text { Storing, processing and } \\
\text { communicating functions of a } \\
\text { hardware or software } \\
\text { component. } \\
\text { Basics on Operating Systems. }\end{array}$ & $\begin{array}{l}\text { Attempting to solve problems by } \\
\text { means of simple procedural and/or } \\
\text { declarative programming } \\
\text { techniques. } \\
\text { Recognising the basic function of a } \\
\text { computer component or system. }\end{array}$ \\
\hline $\begin{array}{l}\text { Presenting } \\
(\sim 10 \%)\end{array}$ & $\begin{array}{l}\text { Text formatting. } \\
\text { Slide presentation. } \\
\text { Binary number representation. } \\
\text { Coding/decoding. } \\
\text { Data reports. Charts. }\end{array}$ & $\begin{array}{l}\text { Using a word processor. } \\
\text { Building a slide presentation. } \\
\text { Converting binary to decimal and } \\
\text { vice-versa. } \\
\text { Using ICT presentation tools and } \\
\text { techniques for document and } \\
\text { communication purposes. }\end{array}$ \\
\hline $\begin{array}{l}\text { Communicating } \\
(\sim 20 \%)\end{array}$ & $\begin{array}{l}\text { The concept of information as } \\
\text { knowledge increase. } \\
\text { Messages, protocols, } \\
\text { communication problems } \\
\text { (reliability, security, ...). } \\
\text { The client-server paradigm: } \\
\text {-the e-mail case study; } \\
\text {-the web case study. }\end{array}$ & $\begin{array}{l}\text { Using standard communication tools } \\
\text { (e-mail, chat, forum). } \\
\text { Configuring an e-mail client. } \\
\text { Configuring a web browser. } \\
\text { Recognising standard } \\
\text { communication failure messages. }\end{array}$ \\
\hline
\end{tabular}


Table 2. Tools and ICT areas

\begin{tabular}{|c|c|c|}
\hline OPERATION & TOOLS & ICT Areas \\
\hline Searching & $\begin{array}{l}\text { Tape-readers, CD/DVD readers. } \\
\text { Simple databases. WEB. }\end{array}$ & $\begin{array}{r}\text { Data, } \\
\text { Systems }\end{array}$ \\
\hline Analysing & $\begin{array}{l}\text { 'Ad hoc' tools for illustrating the syntax } \\
\text { analysis process of a freely chosen grammar. } \\
\text { Text editor, web browser, binary editor. } \\
\text { Scanner + image processor. }\end{array}$ & Languages \\
\hline Structuring & $\begin{array}{l}\text { Hypertext/hypermedia developer. } \\
\text { Spreadsheet processor. 'Ad hoc' classifier. } \\
\text { File system of an operating system. }\end{array}$ & Data \\
\hline Processing & $\begin{array}{l}\text { Computer components. 'Ad hoc' simple CPU } \\
\text { simulators. Developing environments for } \\
\text { educational programming languages. } \\
\text { 'Ad hoc' software for testing simple declarative } \\
\text { solutions. }\end{array}$ & $\begin{array}{r}\text { Programming, } \\
\text { Systems }\end{array}$ \\
\hline Presenting & $\begin{array}{l}\text { Word processor. Slide developer. Spreadsheet } \\
\text { processor. }\end{array}$ & Data \\
\hline Communicating & $\begin{array}{l}\text { Internet communication tools. A net game } \\
\text { (e.g. based on chatting) for consolidating the } \\
\text { information concept. } \\
\text { 'Ad hoc' software for illustrating the protocol } \\
\text { and communication failure concepts and } \\
\text { messages. }\end{array}$ & $\begin{array}{r}\text { Data, } \\
\text { Systems, } \\
\text { Languages }\end{array}$ \\
\hline
\end{tabular}

Of course, programming is not intended as just 'coding': it is problem solving, algorithm discovering/choosing/adapting. The language used in the laboratory should have some educational features which make it clear, attractive and friendly for this age; currently adopted languages do not belong to this category.

Some declarative tools and techniques should be considered in order to apply the 'what/how-to' distinction. An 'always terminating' language hence not Turing-complete (Rogers 1967) - such as SQL or QBE - can be adopted if this can simplify the task.

The 'net-centric' new point of view of ICT has been considered in the Communicating operation; the client/server paradigm is introduced and investigated under two well-known cases: e-mail and http.

In the following three remaining years, time and attention will be given to some operation instead of others depending on the area and sub-area of the Secondary School. 


\section{A FIRST EXPERIENCE AND CONCLUSIONS}

The method has recently been applied to generate a curriculum and a detailed activity plan for all years of the new Primary School (Taffurelli 2001). The initial part of the plan has also been applied and tested with encouraging results in the 'G. Gallina' Elementary School in Venice, under the supervision of Pietro Tonegato, a teacher involved in a project promoted by IRRE del Veneto, a regional educational research institute.

The test was done in October 2000 with pupils of the first level (i.e. 6 years old) and was mainly based on the use of traditional tools, like boxes and coloured paper shapes. Ad hoc software has also been used just as selfassessment tools and to further motivate the pupils. More information (in Italian) on this experience and the software tools used can be found on the IRRE del Veneto web site [http://www.irre.veneto.it/informatica].

The aim of the test was not to follow the hype of introducing computers in the schools and using them in almost any subject. Instead, it was giving strength to the idea that it possible to view ICT as a subject for study with a solid foundation even from the beginning of the Compulsory School.

A first version of this paper has already influenced a proposal for an Italian National Curriculum of Technological Education for the new Primary School. Of course, much work needs to be done to make it effective and shared by all the teachers involved.

Nobody knows weather or when this will happen. We don't know how the new Italian government will continue to effect the School System Reform and the ICT education challenge. Nonetheless, we claim the method here outlined permits to design an ICT National Curricula for all countries with reasonable and useful compromises between the Scientific and Technological views of ICT.

\section{REFERENCES}

IEEE-ACM (2000) The Joint Task Force on Computing Curricula (IEEE Computer Society Association For Computing Machinery). Computing Curricula 2001,(draft).

[http://www.computer.org/education/cc2001/report/cc2001-draft.pdf]

Italian Parliament (2000) Legge-quadro in materia di riordino dei cicli dell'istruzione (Reorganization of Education System Act). Gazzetta Ufficiale n. 44, 23 February 2000, pp. 39. Also available at: [http://www.istruzione.it/news/2000/testo_rifcicli.htm].

Rogers, H. (1967) Theory of Recursive Functions and Effective Computability. McGraw-Hill, New York.

Stoll, C. (1999) High-Tech Heretic: Why Computers Don't Belong in the Classroom and Other Reflections by a Computer Contrarian. Bantam Doubleday Dell, New York.

Taffurelli, E. (2001) Il Curriculum di Informatica nella Nuova Scuola di Base. Tesi di Laurea, Università $\mathrm{Ca}$ ' Foscari di Venezia. 
UK (1999) The ICT National Curriculum for England.

[http://www.nc.uk.net/download/cICT.pdf] 8.5.2001

\section{BIOGRAPHY}

Giuseppe Callegarin received a Laurea in Scienze dell'Informazione at the University of Pisa in 1978. He started to teach Informatics in 1980 writing several high school textbooks on this discipline. He has been involved in several national projects on ICT education as a commission member and/or as a teacher trainer. Since 1996 he extended the teaching experience both to elementary and university levels. His current research activities at IRRE del Veneto are mainly concerned with distance teacher training, educational programming languages design and ICT curriculum development.

Agostino Cortesi received a Laurea in Mathematics at the University of Padova in 1986, and a PhD in Applied Mathematics and Computer Science in 1992 at the same University. In 1992/93 he was a post-doc research associate at the Dep. of Computer Science at Brown University (USA). In 1994 he joined the Dept. of Computer Science at $\mathrm{Ca}^{\prime}$ Foscari University, Venice (Italy) where he is now appointed as Associate Professor. Currently, he gives classes on Programming and Software Engineering. His main research interests concern programming languages theory and static analysis techniques. 